\title{
Modeling and simulation of a hybrid vehicle with two-wheel drive using a multidisciplinary approach
}

\author{
Nissrine MHAITI, Mohammed RADOUANI, Benaissa EL FAHIME
}

\begin{abstract}
The first cars in the history were purely mechanical devices and were designed based on the model of carriages drawn by horses. Since then, automobiles are much developed and represent a marvel of complex interdisciplinary engineering. Indeed, automakers have more and more integrated new technologies in vehicles to meet customer needs. Among these new technologies, there are hybrid vehicles that were developed to overcome the problems of the environment's pollution and to avoid energy crises.
\end{abstract}

In this work, one type of hybrid vehicle was focused on, which is the electric hybrid vehicle with two-wheel drive. Various subsystems of this vehicle is presented and its dynamic model is developed using AMESim software. The operating New European Driving Cycle (NEDC) is used to compare our simulation results and to optimize the functioning of the system.

Keywords-Modeling, Simulation, Hybrid Electric Vehicle, Two-wheel drive, multidisciplinary approach, AMESim software.

\section{Introduction}

The analysis of multibody systems had a remarkable evolution the last few years. This is due to the development of calculation resources provided by the Information Technologies. Today, it constitutes a scientific discipline in its own, that has progressed very quickly under the influence of robotics and aerospace industries as well as vehicle manufacturers.

One of these multibody systems are the hybrid electric vehicles that often represent an interesting complex dynamic system that require a multiphysic approach for modeling and simulation to make sure that they properly behave. These vehicles contain more and more electrical components and the energy storage devices, such as Li-ion batteries, super capacitors and fuel cells are introduced into the next generation their powertrains.
In this context, this paper present different characteristics of the hybrid electric vehicle's configuration and we propose a model of a HEV with two-wheel drive. This vehicle is a parallel hybrid vehicle in which we replace two non-driving wheels by in-hub motors in a perspective of full-hybrid vehicle. The model of our system is made under a multiphysics modeling software and the simulation results are presented comparing to the operating cycle NEDC.

electric vehicles (HEV) that contain a conventional propulsion system and an electric propulsion system [1].

The connection between the components of the energy flow circuits and control ports represents the architecture of the hybrid vehicle. It exist three main classes of these architectures [2] shown in figure 1:

- Series hybrid vehicle [3]: In this configuration, Fig. 1 (a), the power required for the vehicle's movement is provided by the electric motor only. The ICE's is used to supply the generator that supplement the batteries and charge them when they fall below the battery state of charge level. In this architecture, the level of pollutant emissions is low because the engine operates at a high efficiency, but the energy is loss in the driveline.

- Parallel hybrid vehicle [3]: For parallel architecture, shown in Fig. 1 (b), the ICE represents the main power source and both the batteries and the electric motor constitute the energy dumper. This vehicle has the ability to operate with engine alone, electric motor only, or with both motor and engine supplying torque.

- Series-Parallel hybrid vehicle [4]: Fig. 1 (c) shows the third architecture, which is a combination of both series and parallel HEVs. It can operates as a series or parallel HEV and because of that the fuel efficiency and drivability can be optimized based on the vehicle's operating mode.

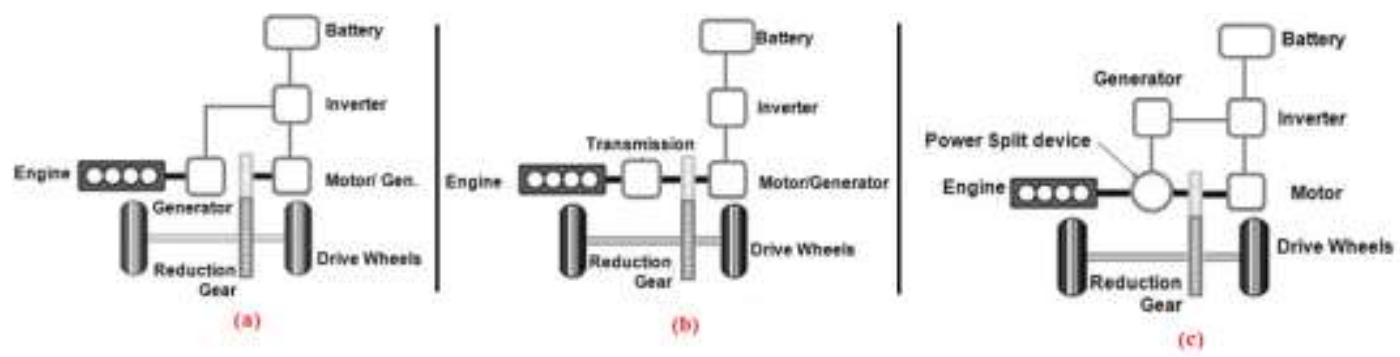

Figure 1. Hybrid vehicle' configurations 


\section{A. Hybrid vehicle with two-wheel drive: description}

The HEV with two-wheel drive has a configuration of a parallel hybrid vehicle but with a different architecture. This architecture's principal is to associate to the classical conventional thermal power train, a propulsion chain on the rear axle with two in-wheel motors, also called hub motors [5].

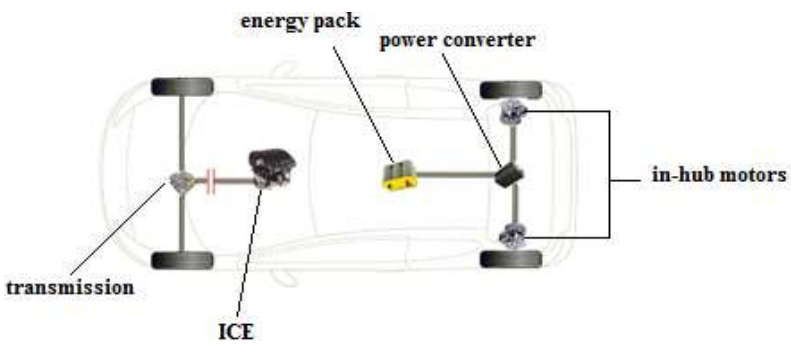

Figure 2. Architecture of HEV with two-wheel drive.

Fig. 2 presents various components of our system. It consists of an Internal Combustion Engine mounted on the front axle, two electric motors mounted on the wheels of the rear axle, of an energy pack that include the batteries and the ultra-capacitor, power converters and a control unit.

\section{MODELING OF HEV WITH TWO WHEEL-DRIVE}

\section{A. Description of modeling and simulation tool}

The hybrid vehicle with two-wheel drive, as a multibody system, requires multiphysics modeling using a modeling and simulation tool devoted to this purpose

In this paper, the modeling tool used to implement a blocks diagrams model of our system is AMESim (Advanced Modeling Environment for performing simulations) of LMS International. This software is a dynamic simulation environment of various engineering domains where components' models can be combined harmoniously in an easy to use interface. All libraries in AMESim can be coupled together using its multi-port modeling of physical components and its block-diagram approach for control systems [6].

\section{B. Physical models of subsystems}

\section{1) Internal combustion engine}

The internal combustion engine (ICE) is defined as heat engine that transforms chemical energy released by the fuel into mechanical energy, usually retrieved using a rotary shaft output [7]. More details about the engine operating cycle, its components, as well as its various types are presented in [8] and [9].

In our vehicle, the ICE allows the drive of the front axle and it is mainly used for conventional operating mode. The model used of ICE, shown in Fig. 5, computes the torque, the emissions (CO, HC, NOx, soot) and the fuel consumption as well as the exhaust gas's flow rate and the combustion thermal losses.

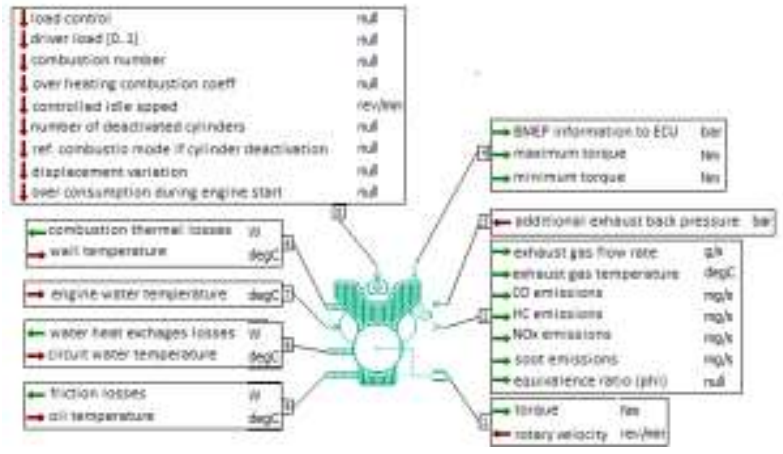

Figure 3. Model of the Internal Combustion Engine

This model gives the Brake Mean Effective Pressure (BMEP) of the engine, the minimum and the maximum engine torque and the power transferred to the cooling system. It receives the exhaust backpressure and nine signals that can be computed by the "ECU for ICE". These signals are listed in Fig. 3 at port 5. It also receives the coolant temperature that is used to determine if the engine is cold or hot.

\section{2) Control circuit of the electric motor}

Two electric motors are incorporated in wheels of the rear axle of the vehicle. These in-wheel motors are modeled as permanent magnet synchronous motors (PMSM) that are used to drive the vehicle's rear axle.

In order to establish a general model of the PMSM, we need to use Park's transformation [10] that allows a transition from three axes $A B C$ to two axes d-q. Electric motor as well as its control circuit are modeled as in Fig. 4:

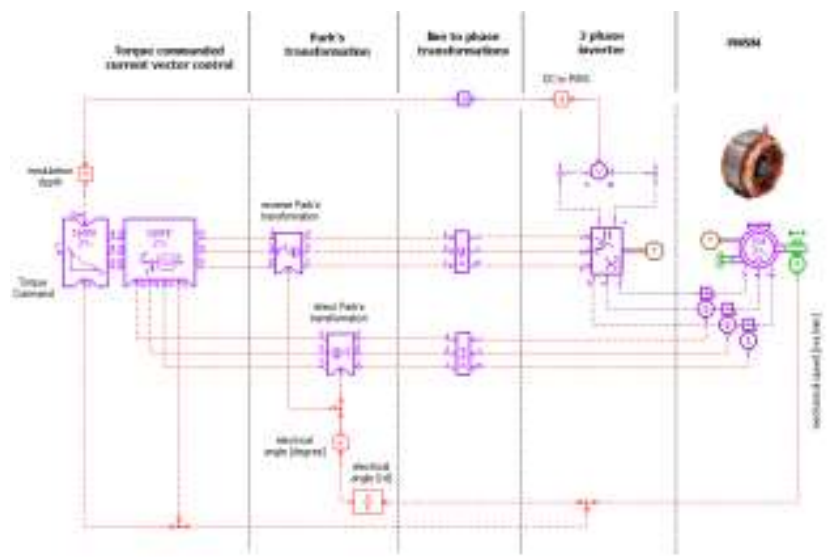

Figure 4. Model of the electric motor and its control circuit

\section{3) Energy pack}

The model of the energy pack for this system comprises a battery pack and an ultra-capacitor pack.

\section{a) Battery pack}

The basic element of each battery is the cell. The battery is generally composed of one or several cells connected in series or in parallel [11] as shown in Fig. 5.

The battery pack is the main power source for vehicle propulsion in full-electric mode. It mainly supplies the DC traction inverters and used to supply power to control unit. 
Proc. of the International Conference on Advances in Mechanical and Automation Engineering - MAE 2016 Copyright (C) Institute of Research Engineers and Doctors. All rights reserved. ISBN: 978-1-63248-102-3 doi: 10.15224/ 978-1-63248-102-3-49

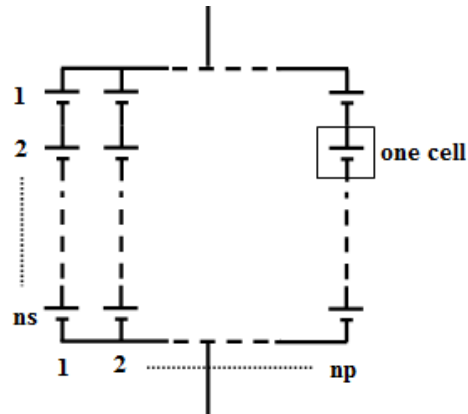

- $n s$ the number of cells in series in one branch

- $n p$ the number of branches in parallel

Figure 5. Cell's arrangement

The model used of the battery can be represented by the equivalent electrical circuit structure in Fig. 6:

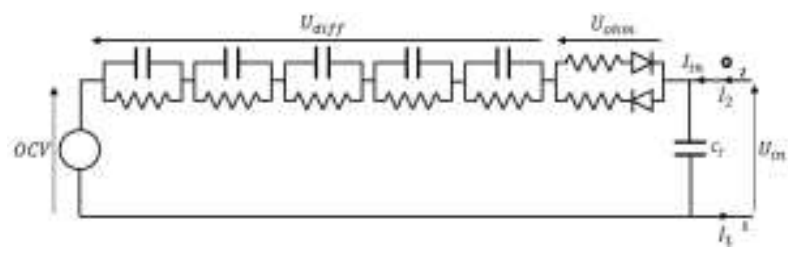

Figure 6. Equivalent electrical circuit of battery

A filtering capacitance is added to the circuit to break potential algebraic loops. The energetic contribution of this filtering capacitance must be negligible in comparison to the battery energy exchange.

The Fig. 7 shows the modeled battery for our model of the hybrid vehicle.

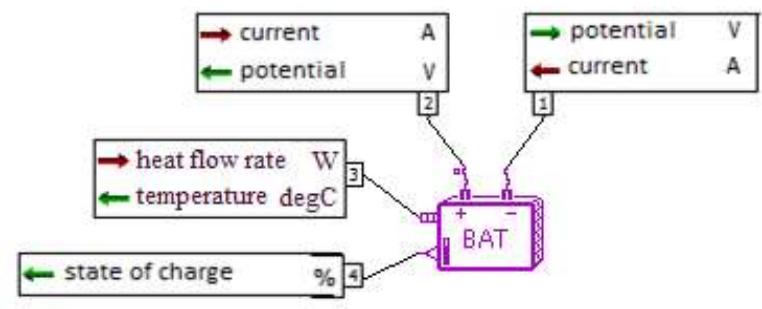

Figure 7. Model of the battery pack.

\section{b) Ultra-capacitor pack}

Ultra capacitors (UCAP) are electrostatic energy storage systems (ESS) that can be used in association with battery systems to absorb or supply high electric power solicitations. They operate in reversible power source that allows very constrained cycles with quick starts and quick decelerations. They are added to the system in order to prevent batteries from premature aging due to high current, and high thermal losses generated inside the cells and packs. The electrical equivalent circuit used to describe the UCAP cell is shown in Fig. 8. It takes into account main capacitance, internal resistance and electrical leakage.

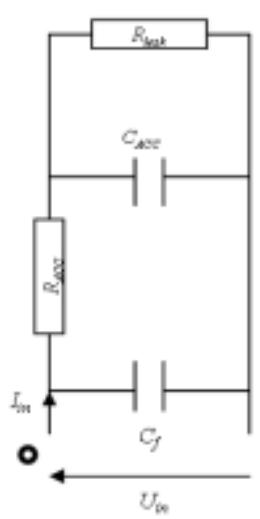

Figure 8. Equivalent electrical circuit of UCAP

The model used of the ultra-capacitors pack is represented in Fig. 9

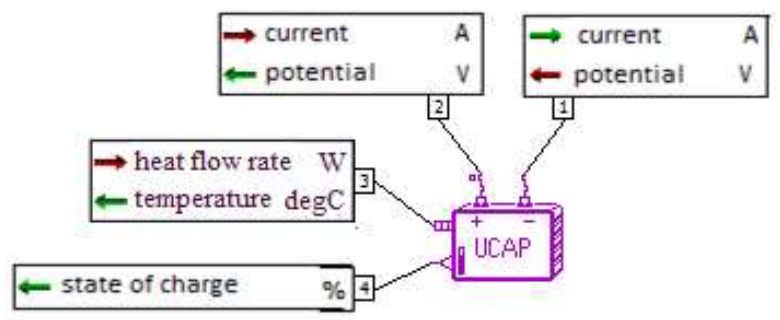

Figure 9. Model of the ulra-capacitors pack

\section{4) Control Unit}

In order to manage the energy flows and to exchange information between various components of our system, we introduce a control unit, shown in Fig. 10.

It manages the power requested to the engine and the electric motor and in function of the cooling temperature received. It calculates the value of the overheating combustion coefficient.

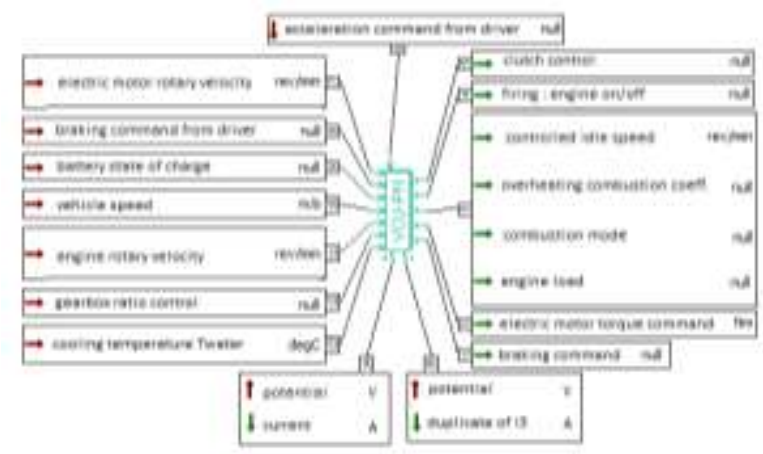

Figure 10. Control unit's model.

The control unit analyses various information received from other elements of the vehicle, which are:

- Acceleration, braking commands and gearbox ratio from the driver

- Rotary velocity from the electric motor

- Rotary velocity from the engine

- State of charge and voltage from the battery

- And the vehicle speed 
Proc. of the International Conference on Advances in Mechanical and Automation Engineering - MAE 2016 Copyright (C) Institute of Research Engineers and Doctors. All rights reserved.

ISBN: 978-1-63248-102-3 doi: 10.15224/ 978-1-63248-102-3-49

\section{Simulation parameters and results}

All sub-models of the system's components are interconnected in order to allow the assembly of the

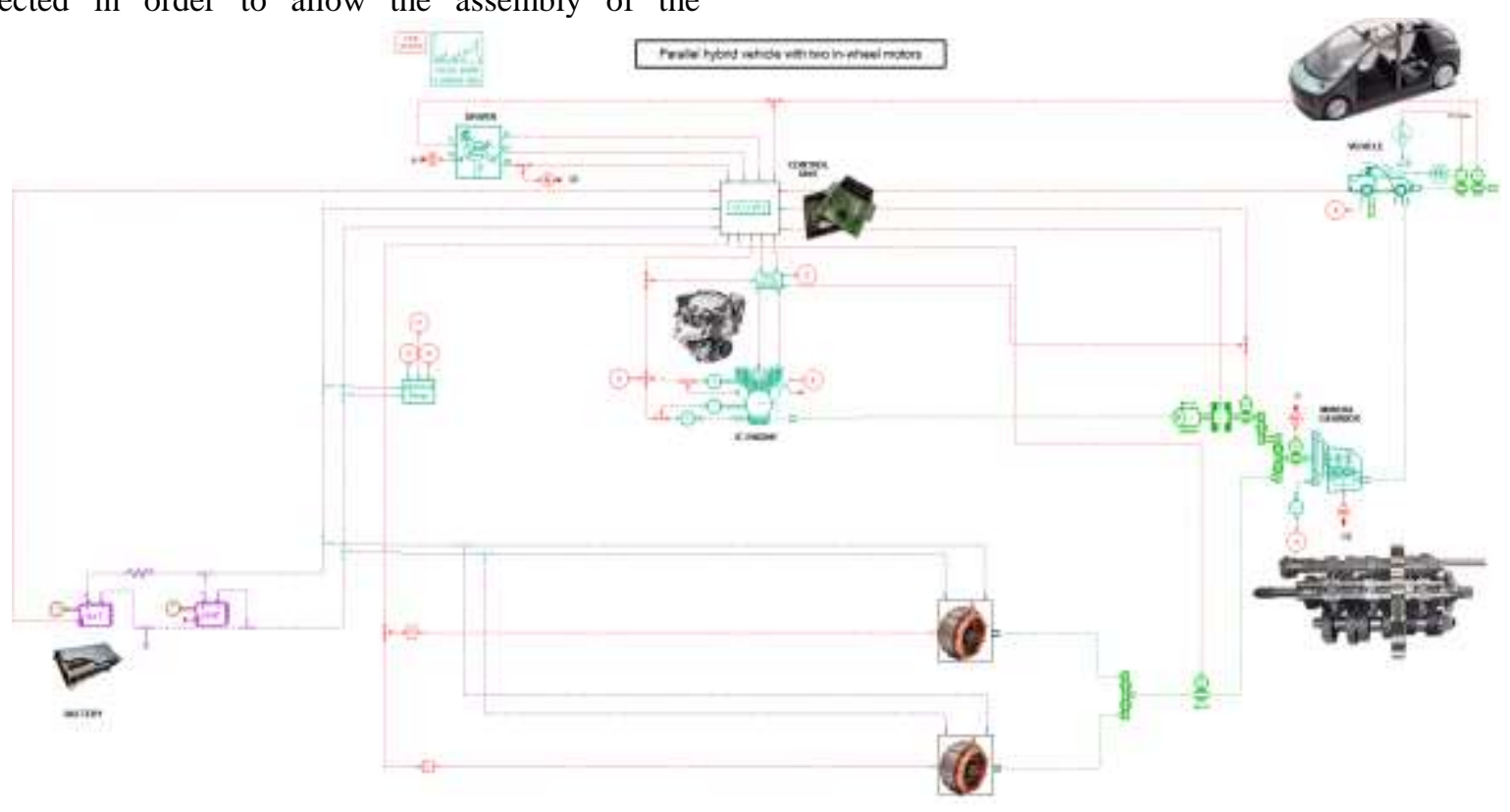

Figure 11. The complete model of the HEV with two wheel drive

In order to complete our model of the hybrid vehicle with two-wheel drive, we added some other sub-models such the model of the vehicle and the one of the gearbox

\section{A. The simulation results}

Using the multiphysic modeling approach under LMS AMESim environment, and after set the parameters, we can simulate the input and output variables of every component of the complete model. These variables can be visualized in evolution curves and compared to those of real models.

To validate the results of the modelled HEV, we compared simulation's results to those of the New European Driving Cycle (NEDC) [12], presented in Fig. 12.

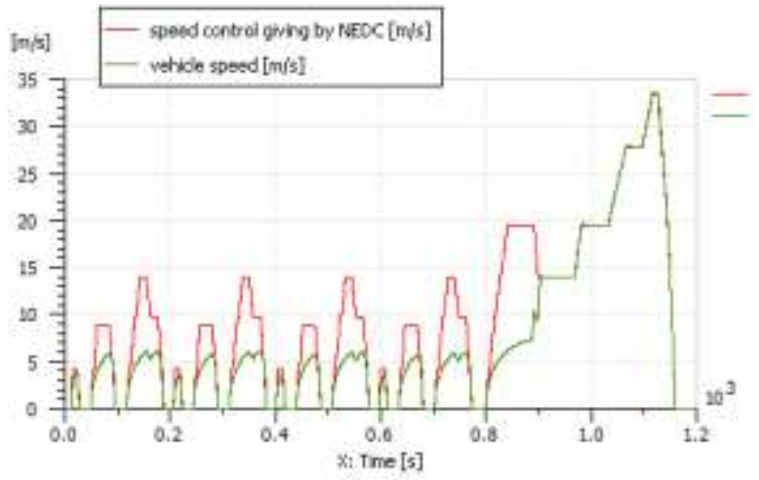

Figure 12. NEDC speed and vehicle model's speed

It is obvious that the speed of the vehicle model follows the speed's set point given by the NEDC cycle. We see a little gap between the two curves which due to addition of ultra-capacitors. complete model of the hybrid vehicle with two wheels drive shown on Fig. 11.

We could also compare, in Fig. 13 the ICE's torque of the model to the ICE's torque command giving by the control unit.

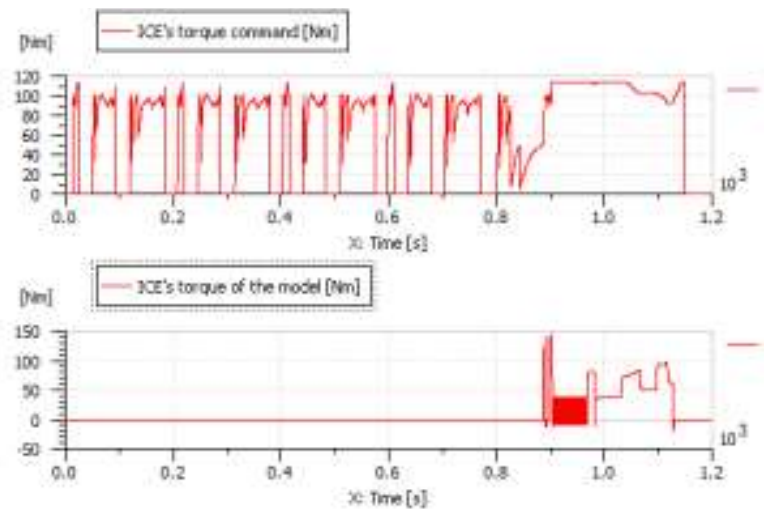

Figure 13. ICE model's torque compared to torque command

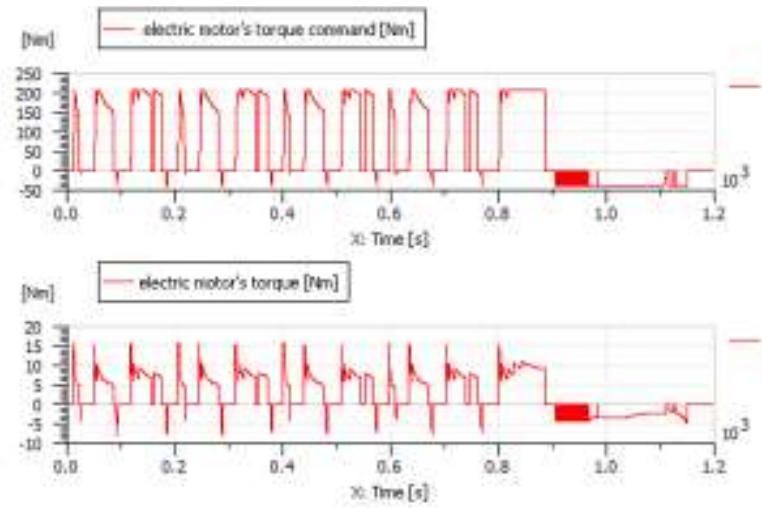

Figure 14. EM model's torque compared to torque command 
From the comparison of electric motor torque command and the torque of our system's model shown in Fig. 14. We notice that the two curves are almost similar and that the ultra-capacitors had ameliorate electric motor's torque.

Finally, we present in Fig. 15 battery regeneration (when it should be recharged) and operating mode of the vehicle (electric or hybrid) in comparison with the state of charge of battery in Fig. 16.

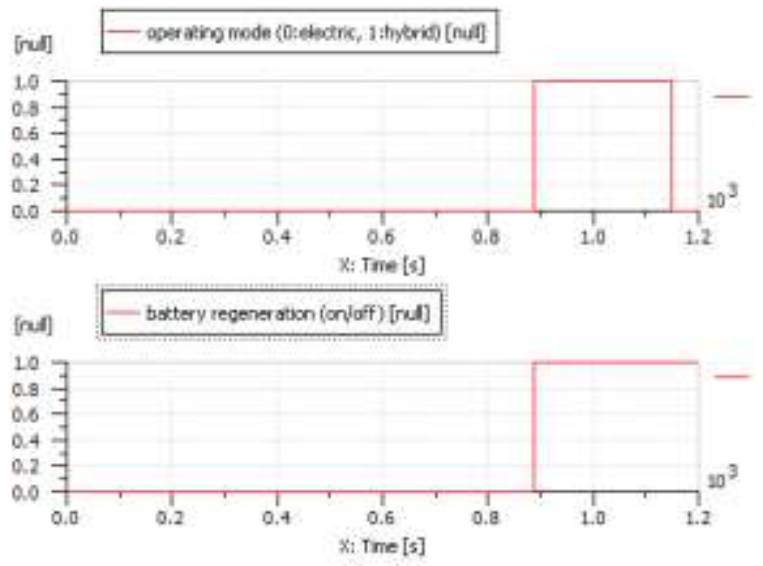

Figure 15. Battery regeneration and the operating mode of the vehicle

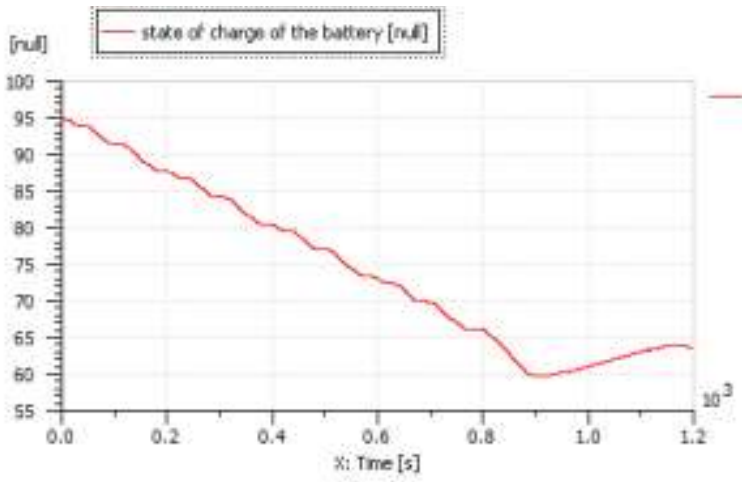

Figure 16. Battery state of charge

This figures show that when the vehicle is in electric mode, the battery don't need to be regenerated and it is progressively discharged. During hybrid mode, the battery is regenerated and charged again.

\section{Iv. CONCLUSION}

In this paper, we presents the main three hybrid architectures that exist. Operating characteristics of each component of hybrid vehicle with two wheel-drive were identified and studied. Then, using a multiphysic modeling and simulation approach, a physical model of this system was developed.

Furthermore, the interconnection of the sub-models of this vehicle's model allowed us to simulate and analyze the vehicle parameters and also to validate the dynamic parameters of our system.

Comparing to work in [article3], we can conclude that by adding ultra-capacitor pack we were able to ameliorate the electric motor's couple as well as the battery's regeneration.

\section{References}

[1] G. Bailly, "Simulation multi-domaines d'un système de propulsion hybride électrique sous l'environnement matlab/simulink ", thesis presented at école de technologie Supérieure of Montréal, Canada 2006

[2] M. Ehsani, Y. GAO, A. Emadi, "Modern Electric, Hybrid electric, and Fuel cell vehicles/ Fundamentals, theory, and Design", ISBN 9781-4200-5398-2 (Hardback), Second Edition, 2010, by Taylor and Francis Group, Power electronics and applications series.

[3] B.T. Fijalkowski, "Automotive Mechatronics: Operational and Practical Issues", ISBN 978-94-007-0408-4, Volume I, 2011, pages 612.

[4] C. Mi, M. A. Masrur, D. W. Gao, "Hybrid Electric Vehicles: Principles and Applications with Practical Perspectives", ISBN 978-0470-74773-5 (cloth), First Edition, 2011, pages 470.

[5] Y. Hung, C. Wub, "A combined optimal sizing and energy management approach for hybrid in-wheel motors of EVs", Applied Energy, Elsevier, 2015, pages 260-271.

[6] LMS International, http://www.lmsintl.com/imagine-amesim-1-dmulti-domain-system-simulation

[7] W. W. Pulkrabek, "Engineering Fundamentals of the Internal Combustion Engine", ISBN 978-0-135-70854-5, 1997, pages 411.

[8] J.B. Heywood, "Internal Combustion Engine Fundamentals", ISBN: 0-07-028637-X, McGraw-Hill series in mechanical engineering Inc., 1988 .

[9] R. Stone, "Introduction to Internal Combustion Engines", ISBN-13: 978-0333550830, 2Rev Ed edition , July 21, 1992, by Palgrave Macmillan, pages 592

[10] V. Reinbold, "Méthodologie de dimensionnement d'un moteur électrique pour véhicules hybrides : optimisation conjointe des composants et de la gestion d'énergie", thesis presented at Université de Grenoble, 2014. French.

[11] H.A. Kiehne, "Battery Technology Handbook (Electrical and Computer Engineering)", ISBN-13: 978-0824742492, Second edition, August 29, 2003, pages 542 .

[12] T.J. Barlow, S. Lathan, I.S. McCare, P.G. Boulter, "A Reference book of driving cycles for use in the measurement of road vehicle emissions", version 3, Published Project Report PPR 354, 2009. 